\title{
Stomach distention as a regulation of fluid intake
}

\author{
ROBERT ENGSTROM and EDWARD DEAUX \\ Antioch College, Yellow Springs, Ohio 45387
}

\begin{abstract}
Rats kept on a 23.5-h/day water-deprivation schedule were given $30 \mathrm{~min}$ access to four solutions, each on a separate test day, which were comprised of the factorial combination of two temperatures (12 $2^{\circ}$ and $37^{\circ} \mathrm{C}$ ) and two $\mathrm{NaCl}$ concentrations $(150$ and $450 \mathrm{mOsm} / \mathrm{kg})$. Food, which was available ad lib, and solution consumption measures were taken. More $37^{\circ} \mathrm{C} 150-\mathrm{mOsm} / \mathrm{kg}$ solution, which has the fastest stomach clearance rate of the four, was consumed than of the other three; short-term and long-term food consumption measures were differentially affected by the solution's temperature and concentration. The hypothesis that cues of preabsorptive satiety originate from stomach distention was supported.
\end{abstract}

Stomach distention is hypothesized to be the cue for preabsorptive satiety of thirst. This hypothesis has been reintroduced to explain an otherwise paradoxical, positive relationship between the amount of water consumed by thirsty animals during a limited exposure period and the water's rate of rehydrating the animal. This relationship was revealed in an investigation of water temperature's effects on satiation (Deaux, 1973), wherein body-fluid osmolality was shown to be lowered faster after ingestion of body-temperature $\left(37^{\circ} \mathrm{C}\right)$ water than after ingestion of cold $\left(12^{\circ} \mathrm{C}\right)$ water. If lowering body-fluid osmolality were the sole cue determining cessation of drinking, drinking should stop after ingestion of less $37^{\circ} \mathrm{C}$ water than $12^{\circ} \mathrm{C}$ water. However, when allowed $1 / 2 \mathrm{~h}$ access to one temperature or the other, water-deprived rats consumed more $37^{\circ} \mathrm{C}$ water than $12^{\circ} \mathrm{C}$ water. Stomach distention, which varies inversely with the rate of absorption, was hypothesized to provide the cue of preabsorptive satiety.

A factor other than temperature which influences the rate of absorption of a solution is the solution's osmolality. Mesoosmotic and hyperosmotic $\mathrm{NaCl}$ solutions initially draw water into the stomach and the gastrointestinal tract after loading, whereas water and hypoosmotic solutions are readily absorbed from the intestine (O'Kelly, Falk, \& Flint, 1958). Considering the measures of stomach clearance of various solutions used by O'Kelly, Falk, and Flint (1958), it is clear that at ambient temperature a hypoosmotic solution of $150 \mathrm{mOsm} / \mathrm{kg}$ clears the stomach faster than a hyperosmotic solution of $450 \mathrm{mOsm} / \mathrm{kg}$. It has also been shown that a hypoosmotic $\mathrm{NaCl}$ solution triggers the initiation of eating faster than a hyperosmotic solution (Kakolewski \& Deaux, 1970a). This shorter latency to the initiation of eating indicates that the hypoosmotic solution lowers body-fluid osmolality at a faster rate than the hyperosmotic solution (Deaux \& Kakolewski, 1971).

Similarly, it has been shown that $37^{\circ} \mathrm{C}$ water leads to eating faster than $12^{\circ} \mathrm{C}$ water and that $37^{\circ} \mathrm{C}$ water is absorbed into the blood faster than $12^{\circ} \mathrm{C}$ water (Deaux,
1973). It therefore follows that $37^{\circ} \mathrm{C}$ water has a faster stomach clearance rate than $12^{\circ} \mathrm{C}$ water.

Considering these characteristics of the temperature and concentration of solutions, the prediction was made that a cold hyperosmotic $\left(12^{\circ} \mathrm{C} 450-\mathrm{mOsm} / \mathrm{kg}\right)$ solution would elicit relatively fast signals of thirst reduction, due to the slowness of its passage out of the stomach and the consequent cues of stomach distention. Furthermore, a relatively greater volume of a warm hypoosmotic $\left(37^{\circ} \mathrm{C}\right.$ $150-\mathrm{mOsm} / \mathrm{kg}$ ) solution would have to be ingested to attain the same level of stomach distention, because it has a relatively fast stomach-clearance rate. In other words, during a limited exposure period, thirsty animals should drink a greater volume of warm hypoosmotic solution than of a cold hyperosmotic solution. In addition to testing this prediction, the present experiment provides information about the influence of the interaction of a solution's temperature and concentration on an animal's intake of that solution. Amounts of warm hyperosmotic and cold hypoosmotic solutions ingested should be between the other two, and, if temperature and concentration are simply additive factors in determining a solution's stomach-distention potential, an interaction should not be found.

\section{METHOD}

\section{Subjects}

Twelve male Holtzman albino rats, 85 days of age and averaging $200 \mathrm{~g}$ body weight on arrival, were individually housed and adapted for 4 weeks to a water-deprivation schedule. Their regimen involved $1 / 2 \mathrm{~h}$ access to water followed by $23.5 \mathrm{~h}$ without water. Food was available ad lib throughout the experiment, except for a total of $15 \mathrm{~min}$ a day, during which time the food was weighed.

\section{Apparatus}

A food tunnel with a removable foodcup was attached to the front of each cage. Also on the front of each cage, a wire bottle holder was devised to accommodate a bottle enveloped in a layer of fiberglass insulation which maintained the solution's temperature during the $1 / 2-h$ exposure period within $3^{\circ} \mathrm{C}$ of the desired temperature. This was determined by temperature measures made at the tubes' orifices with a thermistor probe 
Table 1

Mean Fluid and Food Intake for the Different TemperatureConcentration Solution Conditions \pm the Respective $\mathrm{SE}_{\overline{\mathbf{x}}}$

\begin{tabular}{|c|c|c|c|c|}
\hline \multirow[b]{2}{*}{$\begin{array}{l}\text { CONSUMPTION } \\
\text { MEASURE }\end{array}$} & \multicolumn{4}{|c|}{ CONDITION } \\
\hline & \multicolumn{2}{|c|}{$150 \mathrm{mOsm} / \mathrm{kg}$} & $450 \mathrm{mOsm} / \mathrm{kg}$ & $\begin{array}{l}\text { Osm/kg } \\
37^{\circ} \mathrm{C}\end{array}$ \\
\hline $\begin{array}{l}\text { Solution } \\
\bar{X} \pm \mathcal{L}_{\mathbf{Z}} \text { (in milliliters) }\end{array}$ & $\begin{array}{l}24.92 \\
\pm 0.02\end{array}$ & $\begin{array}{l}30.11 \\
\pm 0.94\end{array}$ & $\begin{array}{l}23.30 \\
\pm 0.59\end{array}$ & $\begin{array}{l}23.00 \\
\pm 1.40\end{array}$ \\
\hline $\begin{array}{l}\text { Pirst Helf Hour Food } \\
\bar{X} \pm \text { L.L.X (in grams) }\end{array}$ & $\begin{array}{l}4.38 \\
\pm 0.27\end{array}$ & $\begin{array}{l}4.71 \\
\pm 0.21\end{array}$ & $\begin{array}{l}1.91 \\
\pm 0.17\end{array}$ & $\begin{array}{l}1.81 \\
\pm 0.21\end{array}$ \\
\hline $\begin{array}{l}\text { Socond Hạlf Hour Food } \\
X_{ \pm} \text {. } \text { K. }_{2} \text { (in erams) }\end{array}$ & $\begin{array}{l}3.04 \\
\pm 0.30\end{array}$ & $\begin{array}{l}3.03 \\
\text { ta.29 }\end{array}$ & $\begin{array}{l}0.77 \\
\pm 0.20\end{array}$ & $\begin{array}{l}0.63 \\
\pm 0.10\end{array}$ \\
\hline $\begin{array}{l}\text { Pollowing } 23 \text { Hour Pood } \\
X \pm S . E . X \text { (in grams) }\end{array}$ & $\begin{array}{c}14.26 \\
\pm 0.71\end{array}$ & $\begin{array}{l}13.86 \\
\pm 0.59\end{array}$ & $\begin{array}{l}14.98 \\
\pm 0.60\end{array}$ & 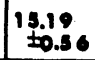 \\
\hline $\begin{array}{l}\text { Tofal } 24 \text { Hour Pood } \\
X \pm \text { S.l. } X \text { (in grams) }\end{array}$ & 21.86 & $\begin{array}{c}23.29 \\
\pm 0.71\end{array}$ & $\begin{array}{l}17.66 \\
\pm 0.68\end{array}$ & $\begin{array}{c}17.63 \\
\pm 0.67\end{array}$ \\
\hline
\end{tabular}

Note $-N=12$.

(Yellow Springs Instrument Model 402 probe and Model 45 telethermometer, accurate to $0.10^{\circ} \mathrm{C}$ ).

\section{Procedure}

During the period of adaptation to the water-deprivation schedule, the rats received room-temperature $\left(24^{\circ} \mathrm{C}\right)$ distilled water. On a test day, each $S$ was exposed to one of the four temperature-solution combinations during the time it was accustomed to access to water. Fluid and food consumption measures were taken every day.

The independent variables were the concentration and temperature of the fluid for consumption. The concentration was $150 \mathrm{mOsm} / \mathrm{kg}$ or $450 \mathrm{mOsm} / \mathrm{kg}$ of $\mathrm{NaCl}$ at a temperature of $12^{\circ}$ or $37^{\circ} \mathrm{C}$, making the design a 2 by 2 factorial. These treatment factors were completely crossed with the $\mathrm{S}$ factor. To expose each rat to each condition, 4 test days were required. The 12 rats were assigned to four groups of 3 , and each group received a different condition from the others on every test day. To offset any effect due to order of presentation over test days, sequencing of conditions to the groups was randomized in a Latin square framework.

A 2-day minimum recovery period was inserted between test days. For this period, all animals received $24^{\circ} \mathrm{C}$ distilled water during their daily $1 / 2-h$ access time. Only after a day in which the group's mean and standard deviation for the consumption of room-temperature distilled water had returned to baseline levels was the testing resumed.

On each test day, solution consumption and three separate food-consumption measures were taken. The amount of solution ingested by each animal during the $1 / 2-h$ access was calculated from the difference in weight of the water bottle before and after exposure. Food consumption was determined in the same manner from the foodcup's weight for three different time periods: the $1 / 2 \mathrm{~h}$ during solution access, the $1 / 2 \mathrm{~h}$ following solution access, and the $23 \mathrm{~h}$ that led to the next day's fluid access period. These measures were taken every day so that no unnecessary new procedures would be imposed on test days.

\section{RESULTS}

The means and standard errors of all the consumption measures are presented in Table 1 . As predicted, a significantly greater amount of warm hypoosmotic solution was ingested than of cold hyperosmotic solution $(\mathrm{t}=3.3969, \mathrm{df}=11, \mathrm{p}<.01)$. An analysis of variance calculated on the volume of solution consumed revealed that the interaction between the temperature and concentration of the solution was significant $(\mathrm{F}=$ $10.5531, \mathrm{df}=1 / 11, \mathrm{p}<.01)$. More of the $150-\mathrm{mOsm} / \mathrm{kg}$ solution was consumed at $37^{\circ} \mathrm{C}$ than at $12^{\circ} \mathrm{C}(\mathrm{F}=$ 21.1884, $\mathrm{df}=1 / 22, \mathrm{p}<.01)$. There was no significant between-temperature difference for the $450-\mathrm{mOsm} / \mathrm{kg}$ solution $(\mathrm{F}<1)$.

More food was consumed during the $1 / 2 \mathrm{~h}$ that the solution was present (the first $1 / 2 \mathrm{~h}$ ) than during the $1 / 2 \mathrm{~h}$ following solution access (the second $1 / 2 \mathrm{~h})(\mathrm{F}=43.1968$, $\mathrm{df}=1 / 11, \mathrm{p}<.01)$. The effect of the solution's concentration on food intake was immediately noticeable. During both the first and second $1 / 2$-h periods, substantially more food was consumed with the hypoosmotic solution than with the hyperosmotic solution $(\mathrm{F}=499.2679, \mathrm{df}=1 / 11, \mathrm{p}<.01)$. Analysis of food intake during the following $23 \mathrm{~h}$ did not reveal that this between-concentration difference in resultant food intake continued during this period. The analysis did reveal a significant main effect for the temperature of the solution $(F=15.6326, \mathrm{df}=1 / 11, \mathrm{p}<.01)$. Greater food consumption following the $37^{\circ} \mathrm{C}$ than following the $12^{\circ} \mathrm{C} \quad 150-\mathrm{mOsm} / \mathrm{kg}$ solution appears to be the central cause of this difference rather than any possible between-temperature difference in the $450-\mathrm{mOsm} / \mathrm{kg}$ condition. This appearance was not supported by the $\mathrm{F}$ for the interaction between concentration and temperature, which was $1.7761(\mathrm{df}=1 / 11, \mathrm{p}>.25)$.

An analysis of the food consumption over the 24-h period beginning with solution presentation did reveal significant differences between the concentrations $(F=$ 386.2748, $\mathrm{df}=1 / 11, \mathrm{p}<.01)$, the temperatures $(\mathrm{F}=$ $6.8377, \mathrm{df}=1 / 11, \mathrm{p}<.05)$, and their interaction $(\mathrm{F}=$ 4.8864, df $=1 / 11, p<.05)$. Further partitioning determined that more food was consumed following the ingestion of $37^{\circ} \mathrm{C}$ than of $12^{\circ} \mathrm{C} 150-\mathrm{mOsm} / \mathrm{kg}$ solution $(F=11.3307, \mathrm{df}=1 / 22, p<.01)$. No difference was found in food intake between the $12^{\circ}$ and $37^{\circ} \mathrm{C}$ $450-\mathrm{mOsm} / \mathrm{kg}$ solution conditions $(\mathrm{F}<1)$.

\section{DISCUSSION}

That significantly more warm hypoosmotic solution than cold hyperosmotic solution was consumed during the 30-min exposure period supports the hypothesis that stomach distention provides the cue for preabsorptive satiety. Since the lowering of body-fluid osmolality has been shown to be an inverse function of the osmolality of the solution consumed (Kakolewski \& Deaux, 1970a) and a positive function of the solution's temperature (Deaux, 1973), it follows that the combination of $37^{\circ} \mathrm{C}$ and $150 \mathrm{mOsm} / \mathrm{kg}$ would lead to more rapid rehydration, due to faster stomach clearance, than the $12^{\circ} \mathrm{C} \quad 450-\mathrm{mOsm} / \mathrm{kg}$ combination. Thus stomach distention, which is inversely related to stomach clearance, is greatest for the cold hyperosmotic solution and least for the warm hypoosmotic solution, allowing more of the latter to be consumed before cues of satiety terminate drinking. 
The significant interaction of the two variables, temperature and concentration, on the consumption of the solution reveals that the suppressive effects on solution intake of these two factors do not combine in a simple, additive manner. With the hypoosmotic solution, the $12^{\circ} \mathrm{C}$ condition resulted in a significant suppression of intake relative to the $37^{\circ} \mathrm{C}$ condition. The mean solution consumption for both the warm and the cold hyperosmotic solution was at the approximate level of the mean for the cold hypoosmotic solution consumption. The $12^{\circ} \mathrm{C} 450-\mathrm{mOsm} / \mathrm{kg}$ solution did not show greater suppression of fluid intake than did either the $450-\mathrm{mOsm} / \mathrm{kg}$ condition within the $37^{\circ} \mathrm{C}$ solution temperature or the $12^{\circ} \mathrm{C}$ condition within the $150-\mathrm{mOsm} / \mathrm{kg}$ solution. This suggests that the suppressive effect of concentration on solution consumption is strong enough in some cases to mask the suppressive effect of a range of temperatures on stomach clearance. Similarly, it is possible that the effect of some temperatures on fluid intake is strong enough to mask the effect of a range of concentrations on stomach clearance. With the four temperature-concentration conditions used in the present experiment, a determination of this possibility cannot be made.

Another possible explanation of the interaction can be excluded on the basis of recent reports: the possibility is that rats are not sufficiently sensitive to gastrointestinal changes, such as stomach distention, for these changes to provide the cue for the cessation of drinking. Davis and Campbell (1973), for example, found that the removal of as little as $3 \mathrm{ml}$ of recently ingested milk solution from a rat's stomach reinduced drinking until the loss was replaced. Sensitivity is also indicated by a strong linear relationship between the temperature of ingested water, in the range from $12^{\circ}$ to $37^{\circ} \mathrm{C}$, and the amount that is consumed (Deaux, 1973). And, by controlling both oropharyngeal (including taste) and postingestional cues, Rabe and Corbit (1973) have recently demonstrated that the $\mathrm{NaCl}$ concentration of the solution reaching the stomach determines the amount of solution ingested, not the concentration of the solution that the animal drinks. They were thereby able to show that the acceptance-rejection curve for $\mathrm{NaCl}$ solutions is a function only of postingestional events. In all, therefore, gastrointestinal factors have been found to have a sensitive regulatory influence on the amount of a solution consumed.

The finding that food consumption during the solution-access period and the $30 \mathrm{~min}$ that followed it was largely determined by the osmolality of the solution was expected on the basis of previous research (Kakolewski \& Deaux, 1970b). During the 23-h follow-up period, no influence of the consumed solution's osmolality on food consumption was found. It follows from these data that solution concentration produces a fast-acting but short-term effect on food consumption. This pattern appears to result from the fact that lowered body-fluid osmolality, which has been shown to trigger and regulate eating in a short exposure period such as that used here (Kakolewski \& Deaux, 1970a, b; Deaux \& Kakolewski, 1971) occurs much more slowly following the ingestion of a hyperosmotic solution than it does after ingesting a hypoosmotic solution. Yet during the subsequent hours, as the $\mathrm{NaCl}$ is removed by the animal's system and usable water is freed, body-fluid osmolality continues to decrease and the amount of food consumed is approximately equal to that eaten following the ingestion of the hypoosmotic solution (i.e., the mean 23-h food consumption for the $450-\mathrm{mOsm} / \mathrm{kg}$ condition was $15.087 \mathrm{~g}$, and for the $150-\mathrm{mOsm} / \mathrm{kg}$ condition it was $14.908 \mathrm{~g}$ ).

The difference in total food intake between temperatures with the $150-\mathrm{mOsm} / \mathrm{kg}$ solution was also expected on the basis of previous research (Deaux, 1973). The ingestion of more warm than cold hypoosmotic solution did result in greater food intake with the warm solution. Whether or not this between-temperature difference was present during the initial stages of eating cannot be determined because of the amount of variability in the first hour of food consumption. However, this difference, as opposed to the difference with osmolality, was apparent during the 23-h follow-up period. The effect of the greater ingestion of the warm than of the cold hypoosmotic solution is present in the long-term food consumption.

In conclusion, the hypothesis that stomach distention cues preabsorptive satiety of thirst was supported by our experimental evidence: rats drank significantly more hypoosmotic warm solution than they did hyperosmotic cold solution. Food intake measures revealed an immediate, but short-term, effect of the solution's concentration and a longer lasting effect of the temperature of the solution. The effect of the solution's temperature on food intake resulted from greater consumption of warm than of cold hypoosmotic solution. A between-temperature difference in solution consumption was not found with the hyperosmotic solution. An explanation of the finding that concentration and temperature do not determine a solution's intake by simply adding their suppressive effects is left to be provided by future research.

\section{REFERENCES}

Davis, J. D., \& Campbell, C. S. Peripheral control of meal size in the rat: Effect of sham feeding on meal size and drinking rate. Journal of Comparative \& Physiological Psychology, 1973, 83, 379-387.

Deaux, E. Thirst satiation and the temperature of ingested water. Science, 1973, 181, 1166-1167.

Deaux, E., \& Engstrom, R. The temperature of ingested water: Its effect on body temperature. Physiological Psychology, $1973,1,152-154$.

Deaux, E., \& Kakolewski, J. W. Character of osmotic changes resulting in the initiation of eating. Journal of Comparative \& Physiological Psychology, 1971, 74, 248-253.

Kakolewski, J. W., \& Deaux, E. Initiation of eating as a function of ingestion of hypoosm otic solutions. American Journal of Physiology, 1970a, 218, 590-595. 
Kakolewski, J. W., \& Deaux, E. The control of initiation of food intake by body-fluid osmolality. Communications in Behavioral Biology, 1970b, 5, 191-194.

O'Kelly, L. I., Falk, J. L., \& Flint, D. Water regulation in the rat: Gastrointestinal exchange rates of water and sodium chloride solution drinking in the rat. Journal of Comparative \& Physiological Psy chology, 1958, 51, 16-21.
Rabe, E. F., \& Corbit, J. D. Postingestional control of sodium chloride solution drinking in the rat. Journal of Comparative \& Physiological Psychology, 1973, 84, 268-274.

(Received for publication February 26, 1974; revision received April 9, 1974.) 